\title{
Effect of Exhaust Duct Position on Wood Vinegar Burning Process
}

\author{
Phineath Than and Keerati Suluksna
}

\begin{abstract}
This research aims to develop a burning tank and experiment for wood vinegar burning process using wood as raw material. To design, and operation of such burning tank require detailed understanding of parameters that affect the system performance. In the research, the device is designed for testing and developing a burning system that can improve the distillation rate of wood vinegar. The developed system consists of two tanks; burning tank and condensing tank. Burning tank made of steel with $400 \mathrm{~mm}$ diameter and $600 \mathrm{~mm}$ long for $15-20$ $\mathrm{kg}$ of wood, provides tight airflow and has two exhaust ducts attached to top and bottom of the tank side. The condensing tank has 24 copper pipes with diameter of $12 \mathrm{~mm}$, and $400 \mathrm{~mm}$ long, resulting in a condensing surface area of $0.36 \mathrm{~m} 2$. The condensing pipes are installed in a 65 liters tank contains cool water with temperature from $30{ }^{\circ} \mathrm{C}$ to $40{ }^{\circ} \mathrm{C}$ which is used as media for removing the heat from those pipe surfaces. In the experiments, two kind of woods will be used to test, fire conditions of air flow rate and moisture of woods are varied and two positions of exhaust duct are investigated. This developed system was tested on exhaust duct positions by using $15 \mathrm{~kg}$ Leucaena leucocephala wood with 5 hours, producing 3.39L and 4.21L by bottom and top duct positions respectively. The experiment results show that the interaction between the positions of exhaust duct is significantly effect on the yield percent of wood vinegar collected. That is the top position can increase the wood vinegar $24 \%$ compare with the bottom position.
\end{abstract}

Index Terms-Exhaust duct, wood vinegar, experiment, parameters, burning tank.

\section{INTRODUCTION}

In rural area, charcoal was made from wood by using an earthen kiln. The woods are often dead wood collected from the forest or sometimes bamboo is used. In addition, the charcoal is then sold or is used for cooking. Traditional kilns release very harmful smoke and pollution into the environment. Recently, newer style of burning tank have been studied to made good quality charcoal and is suitable for adaption wood vinegar during a gasification process.

Wood vinegar or pyro-ligneous acid is distilled liquid obtained from the charcoal burning process. It is a dark brown liquid produce by the combustion of wood under airless conditions. When the vapor is cooled, it condenses into wood vinegar, which contains the principal components are acetic acid, acetone, methanol, wood oils and tars. Wood vinegar is used to improve soil quality, eliminate pests and control plant growth. It is causally growth of stems, tubers,

Manuscript received June 15, 2018; revised August 27, 2018.

The authors are with School of Mechanical Engineering, Institute of Engineering, Suranaree University of Technology, 11 University Avenue, Muang District, Nakhon Ratchasima 30000, Thailand (e-mail: Phineath@yahoo.com, Keerati@sut.ac.th). leaves, roots, flowers, and fruit. Food and Fertilizer Technology Center [1] showing that fruit trees produce increased amounts of fruit after applying wood vinegar in an orchard. It is also safe in the food chain living matters, especially insects that help pollinate plants. There have been many researches into wood vinegar. China and Japan were known as the place has been undertaken research on wood vinegar, while some researchers have also focused on improving animal health by using a compound of wood vinegar mixing in animal food reported by Nakajima, et al. [2]. Design and development of pyrolysis system to produce wood vinegar by using rice husk as a raw material was investigated by Suzilawati [3]. Other researchers include Yamauchi, et al. [4] who investigated wood vinegar made of broadleaf tree bark carbonized has testing effect on red mites by injection into their bodies and Yang, et al. [5] who studied influent of air flow rate and the moisture of fuel on biomass burning behaviors and simulated municipal solid wastes in packed beds. Somsuk, et al. [6] who investigated pyrolysis oven in wood vinegar production by developing heat exchanger. Chalermsan, et al. [7] who produced wood vinegar from rural charcoal kiln and it is used as plant protection. Experiment of wood vinegar produced from pine nut shell continuous pyrolysis was also carried out by Jiang, et al. [8].

However, there is still a lack of detailed or no supporting documents on experimental study of parameters for wood vinegar burning process and develop the distillation rate of wood vinegar using wood as raw material. The advantage of experimental study can improve the distillation rate of wood vinegar and lies in its ability to reveal the detailed behavior of parameters in burning process inside. The research investigates on two positions of exhaust duct. Leucaena leucocephala wood is used as a materiel for the production process. This research contributes better understanding and controlling of the wood vinegar burning process and the performance of parameters in processes.

\section{METHODOLOGY}

\section{A. Design Concepts}

The schematic of wood vinegar processing system is shown in Fig. 1. The system consists of five parts: (1) burning gate, (2) burning tank, (3) Pipe connecting between burning tank to condensing tank, (4) condensing tank, and (5) condensing tubes.

The wood vinegar burning device is designed to contain $15-20 \mathrm{~kg}$ of wood, provides one gate for tight airflow as well as burning. The burning tank uses Liquid Petroleum Gas (LPG) as fuel. The required temperature to heat the 
wood is about $120-430^{\circ} \mathrm{C}$ to give the good quality of wood vinegar, under amount of airless condition. The limit-air known as the incomplete combustion gases that are a mixture of volatile organic compounds pass through the connection pipe to condensing tank which has 24 copper pipes use as condensing tube to be condensed into wood vinegar resulting in a condensing surface area of $0.362 \mathrm{~m} 2$. The condensing pipes are installed in a 65 liters tank contains with cool water which is used as media for removing the heat from those pipe surfaces.

\section{B. Operation and Structure Design}

The burning system consists of two main components; burning tank Fig. 2 and condensing tank Fig. 3. The burning tank has $400 \mathrm{~mm}$ diameter, $600 \mathrm{~mm}$ tall and $1.5 \mathrm{~mm}$ thickness, which uses sand residual as isolation are shown in Fig. 2 is designed for wood burning under airless condition and obtain the heat from the burning gate. The tank is made from sheet metal. The rectangle cubic space at outside tank is used for LPG fuel heating Fig. 4.The capacity of the tank is $0.075 \mathrm{~m}^{3}$ for wood. Two exhaust ducts with a $60 \mathrm{~mm}$ diameter and $150 \mathrm{~mm}$ long, attached to the tank side for more smooth ventilation and experiment investigated.

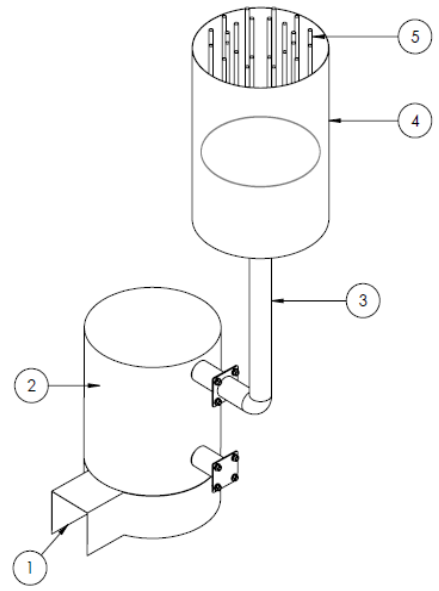

Fig. 1. Schematic of wood vinegar producing system.

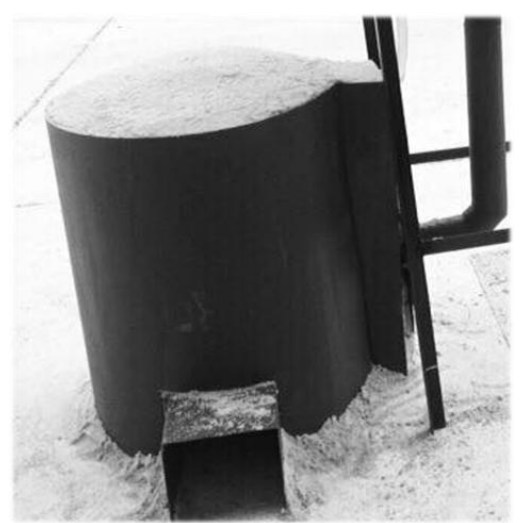

Fig. 2. The burning tanka.

The condensing system is used in the extraction process, allows for raw wood vinegar collection. The burning tank is designed for a concept; by experiment of parameters for wood vinegar burning process using wood as raw material and thermal decomposition of organic substances harmful gases will pass on through the copper tube, cool water with temperature from $30{ }^{\circ} \mathrm{C}$ to $40{ }^{\circ} \mathrm{C}$ is used as media for removing the heat from those pipe surfaces Fig. 3. It increases the performance of condensing and also reduces the greenhouse effect.

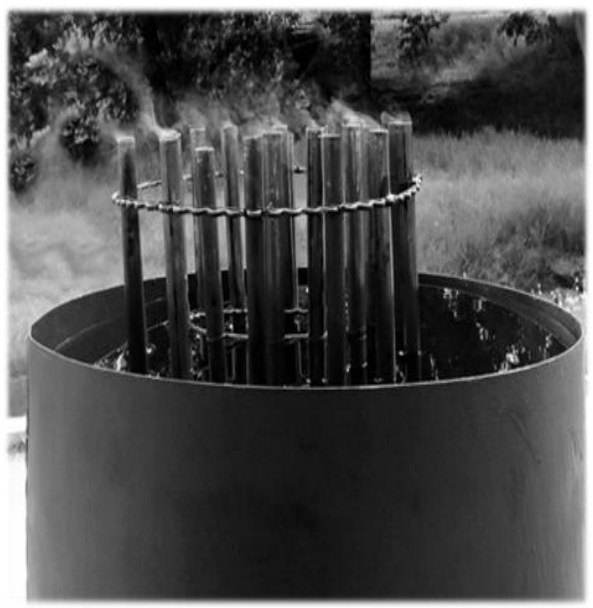

Fig. 3. The condensing tank.

\section{EXPERIMENT}

In this research, a factorial design of experiments with seven replicates, has been developed in order to study the influence of positions of exhaust duct, fire conditions of air mass flow rate, moisture of woods and two kind of woods are used to test based on yield percent of wood vinegar collected, and to determine the optimal exhaust duct position for producing wood vinegar.

In this research, the burning tank is developed for the production of wood vinegar, by using LPG as fuel. A byproduct from wood vinegar production is charcoals which can be sold or use as a solid fuel. The influences of exhaust duct positions is investigated by testing two replicates, fire conditions of air mass flow rate are varied to test with 3 replicates, moisture of woods inside are removed $0 \mathrm{~kg}, 1 \mathrm{~kg}$, $2 \mathrm{~kg}$ and two kind of woods are used to test. Two kinds of wood; Leucaena leucocephala and Acacia are used in the experiment as raw materials to produce the wood vinegar. In each experiment $15 \mathrm{Kg}$ of wood is used. Finally, the yield percent of wood vinegar production is performed.

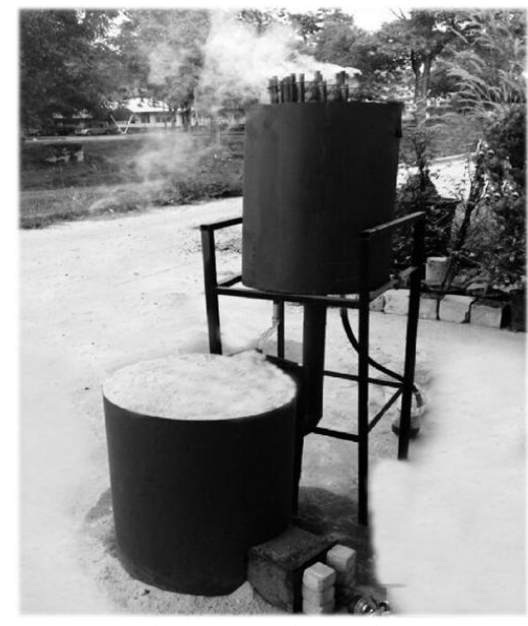

Fig. 4. Operation testing

The steps to perform testing are following:

1) Leave the fresh Leucaena leucocephala wood for 25-30 days before conducting an experiment.

2) Put $15 \mathrm{~kg}$ of the Leucaena leucocephala wood in the 
burning tank, and set up LPG in the burning gate.

3) Burn the LPG. Start to time, measure the temperature every 1 hour in burning tank.

4) Notice the color of the wood vinegar product from the condensing tank. If the color turns to red-brown liquid, which means it is becoming raw wood vinegar. Collection the vinegar drops from the wood vinegar drain.

5) If the color of wood vinegar turns to dark brown color, which means the moisture substance in those wood are all evaporated and the wood become a good charcoals.

6) Stop to time after five hours. The period of timing since beginning is the process time of producing wood vinegar. Leave the burning tank and the charcoal cool down for 6 hours.

7) Measure the amount of obtained charcoal, wood vinegar and ash.

8) Repeat the step 1-7, with more replicates by changing conditions.

9) Close the raw wood vinegar in the bottles or tanks for 3 months in order to separate light oil, sour vinegar and tar. Remove the light oil and tar out by using sour wood vinegar only.

\section{RESUlTS AND DisCUSSION}

The burning system is constructed, and tested its operation.

Results from the operation test with positions of exhaust duct on Leucaena leucoceph wood, are following Table I below:

TABLE I: Productions FROM TESTING

\begin{tabular}{|c|c|c|c|c|}
\hline \multirow{2}{*}{ Testing } & \multirow{2}{*}{ Unit } & \multicolumn{2}{|c|}{ Exhaust Duct Position } & \multirow{2}{*}{ Percent } \\
\cline { 3 - 4 } & & Bottom & Top & \\
\hline Wood (Dn 5-8cm) & $\mathrm{Kg}$ & 15 & 15 & $0 \%$ \\
\hline Time & $\mathrm{h}$ & 5 & 5 & $0 \%$ \\
\hline Fuel & $\mathrm{kg}$ & 0.5 & 0.5 & $0 \%$ \\
\hline Wood vinegar & $\mathrm{ml}$ & 3392 & 4215 & $24 \%$ \\
\hline Charcoal & $\mathrm{Kg}$ & 8.1 & 6.2 & $31 \%$ \\
\hline Ash & $\mathrm{Kg}$ & 0.1 & 0.2 & $50 \%$ \\
\hline
\end{tabular}

The average interval of the measured temperature at the burning tank while happening the wood vinegar process is about $68-410^{\circ} \mathrm{C}$ that meets the desired temperature.

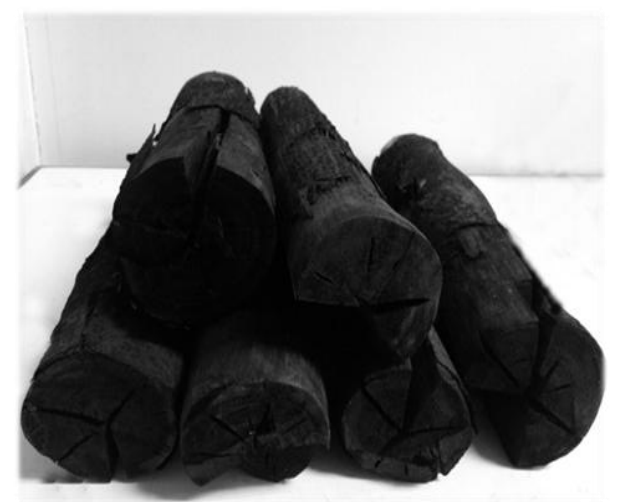

Fig. 5. The obtained charcoal.

Results from study the influence of position exhaust duct on the yield percent of wood vinegar collected, with 2 replicates. In each experiment uses $0.5 \mathrm{~kg}$ of LPG as fuel.
The experiment results are shown in Table II.

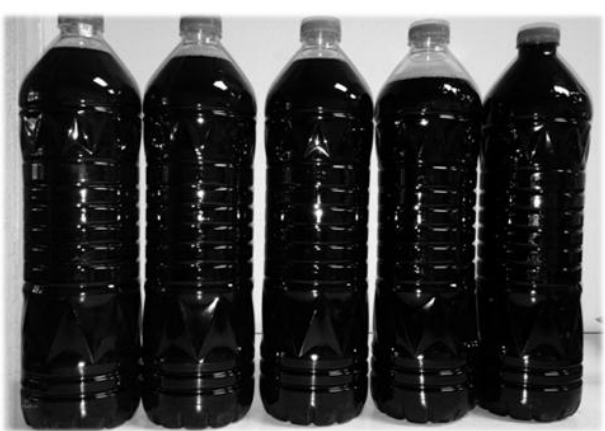

Fig. 6. The obtained raw wood vinegar.

TABLE II: Amount of Wood Vinegar with Respect to Time at EACH Exhaust DuCT Position

\begin{tabular}{|c|c|c|c|l|}
\hline \multirow{2}{*}{ Time (h) } & \multicolumn{2}{|c|}{ Burning tank $\left({ }^{\circ} \mathrm{C}\right)$} & \multicolumn{2}{c|}{ Wood Vinegar $(\mathrm{ml})$} \\
\cline { 2 - 5 } & Bottom & Top & Bottom & Top \\
\hline 1 & 130 & 68 & 10 & 0 \\
\hline 2 & 165 & 94 & 270 & 335 \\
\hline 3 & 240 & 138 & 875 & 1220 \\
\hline 4 & 326 & 340 & 1210 & 1420 \\
\hline 5 & 410 & 338 & 1027 & 1240 \\
\hline
\end{tabular}

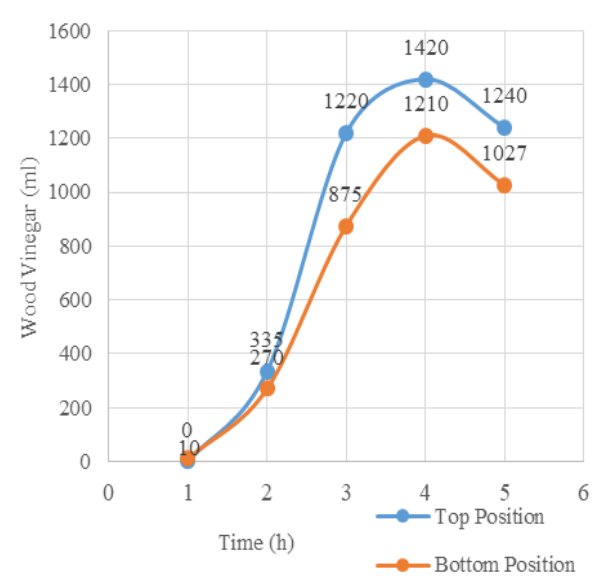

Fig. 7. Wood vinegar condensation performance vs. time.

Fig. 7 shows the condensing performance of wood vinegar in each position, top and bottom of exhaust duct vs. time for the $15 \mathrm{~kg}$ of wood Leucaena leucoceph by using 0.5 $\mathrm{kg}$ of LPG fuel. The initial, the bottom position produced wood vinegar $10 \mathrm{ml}$ in the first hour while the top position there is no wood vinegar condensed. It seen that the bottom position started evaporate moisture from the wood in the first stage. From 2nd-3rd hour the temperature of bottom and top is increasing rapidly, but the top position is able to produce wood vinegar much more than the bottom position. During the 3rd -4 th hour the temperature of bottom and top jump to $326{ }^{\circ} \mathrm{C}$ and $340{ }^{\circ} \mathrm{C}$. In this stage, it seen that the wood is strongly self-burning which can produce wood vinegar maximum. The wood vinegar began to slight fall condensation. After the tank is cold down, the bottom position there is many wood vinegar stuck to the burning surface while the top position there is less than. It also seen that the current of gasification flow in the bottom position is hard to flow the hot gas out by the exhaust duct, so some of wood vinegar condensed in the tank and remain the temperature increasingly. The top position allowed more smooth gasification flow to condensing tank to condense into wood vinegar and release heat as well. 


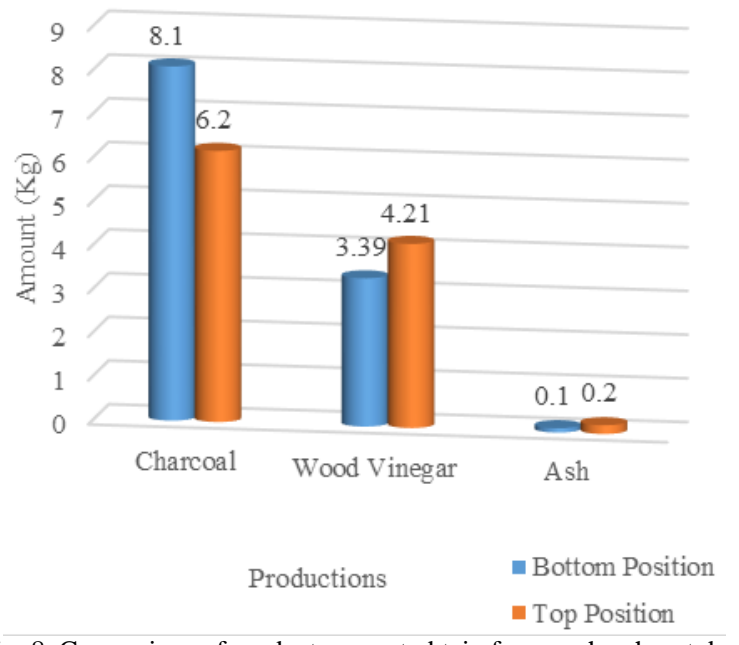

Fig. 8. Comparison of product amount obtain from each exhaust duct position.

Fig. 8 shows that top exhaust duct position gives the highest yield percent of raw wood vinegar for the production of wood vinegar by using this burning system. It is also interesting to note the development of the wood vinegar as time goes on. The first distillate is almost entirely water and it is not until about the 2nd hour that the liquor slowly darkens and contains increasing amounts of acid. The measured temperature at the burning tank is about $68-410^{\circ} \mathrm{C}$ that meets the desired temperature as prior design. If the temperature is below about $150^{\circ} \mathrm{C}$, the wood vinegar will consist mainly of water. And if the temperature is above $400^{\circ} \mathrm{C}$, it will consist mainly of tar.

The product of the designed burning tank is wood vinegar Fig. 6 and the by-products are charcoals Fig. 5 and the noncondensable wood gases. The wood vinegar is very valuable for agriculture. The charcoal can be used as solid fuel for cooking or can be sold.

The wood vinegar and the charcoals, produced by this burning system will make income for the investors. The first investment of the burning tank is about 5000 Baht. It is a simple burning tank structure, low investment but make high gain.

\section{CONCLUSIONS}

In the paper, the applicability of new system in replacing traditional system for wood vinegar production can be determined. From the experiment results show that the interaction between the positions of exhaust duct is significantly effect on the yield percent of wood vinegar collected.

The wood vinegar has great potential in many fields especially in agriculture. Further research is important in assessing the optimum size and shape of wood for making higher condensing of wood vinegar. The households' incomes are expected to increase when the investor use the burning system.

\section{ACKNOWLEDGMENT}

The author would like to thank Suranaree University of Technology (SUT) for the financial support of this research.

\section{REFERENCES}

[1] Wood vinegar. (2005). Food \& Fertilizer Technology Center. Wood Vinegar. [Online]. Available: http://www.agnet.org/library/pt/2005025

[2] S. Nakajima, M. Tsuji, K. Iwasaki, and T. Yoshida, "Effect of wood vinegars on the growth of tomato, eggplant, "Agricultural Science, vol. 42, pp. 59-68, 1993.

[3] I. Suzilawati, Design and Development of Pyrolysis System to Produce Wood Vinegar, 2013.

[4] K. Yamauchi and Y. Matsumoto,"Wood vinegar from broadleaf tree bark carbonized at low temperature has exterminating effect on red mites by invading into their bodies," Academia Journal of Agricultural Research, vol. 145-159, 2016.

[5] Y. B. Yang, V. N. Sharifi, and J. Swithenbank, "Effect of air flow rate and fuel moisture on the burning behaviours of biomass and simulated municipal solid wastes in packed beds," Fuel, vol. 83, 2004

[6] N. Somsuk and T. Wessapan, "Development of a heat exchanger used with pyrolysis oven in wood vinegar production," ResearchGate. Pathumthani, 2009.

[7] Y. Chalermsan and S. Peerapan, "Wood vinegar: By-product from rural charcoal kiln and its role in plant," Asian Journal of Food and Agro-Industry, pp. S189-S195, 2009.

[8] E. Jiang, Z. Chenxi, Q. Liyuan, and A. Chen, "Experiment of wood vinegar produced from pine nut shell continuous pyrolysis," Transactions of the Chinese Society of Agricultural Engineering, vol. 30, pp. 262-269, 2014.

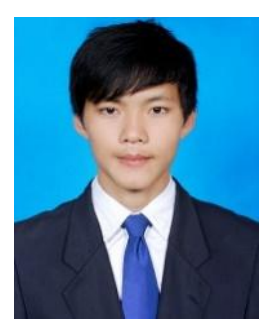

Phineath Than received the B.E. degrees in mechanical engineering from Institute of Technology of Cambodia in 2016 and received BA. degree in English language from University of Puthisastra, Cambodia in 2016. He became a member of Students' Association of Institute of Technology of Cambodia (SACIT) in 2015 and worked as a mechanical engineer at MT Engineering (Cambodia) Co., Ltd in 2016. Currently, he is pursuing the M.E. degree in mechanical and process system engineering at Suranaree University of Technology, Thailand. His research interests include air conditioning cycle bench, fire fighting system, plumbing design, fly wheel project, and wood vinegar experiments.

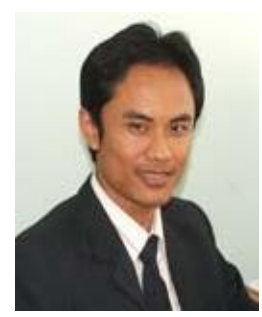

Keerati Suluksna is an assistant professor in mechanical engineering in Suranaree University of Technology, Thailand. $\mathrm{He}$ is the head of Compotation Mechanics Research Group (CMRG). His research interests include computer simulation, CAE, CFD, and flow modeling. 